\title{
PERCEPÇÃO DE DOCENTES SOBRE O PROCESSO DE APRENDIZADO EM ADMINISTRAÇÃO DE ENFERMAGEM*
}

Cristiano Caveião1, Ivete Palmira Sanson Zagonel², Izabel Cristina Meister Coelho ${ }^{3}$, Aida Maris Peres ${ }^{4}$, Juliana Helena Montezeli ${ }^{5}$

1Enfermeiro. Mestre em Biotecnologia. Faculdades Integradas do Brasil/Faculdade Pequeno Príncipe. Curitiba-PR-Brasil. ${ }^{2}$ Enfermeira. Doutora em Enfermagem. Docente na Faculdade Pequeno Príncipe. Curitiba-PR-Brasil. ${ }^{3}$ Médica. Doutora em Clínica Cirúrgica. Docente na Faculdade Pequeno Príncipe. Curitiba-PR-Brasil. ${ }^{4}$ Enfermeira. Doutora em Enfermagem. Docente na Universidade Federal do Paraná. Curitiba-PR-Brasil. ${ }^{5}$ Enfermeira. Mestre em Enfermagem. Docente na Universidade Estadual de Londrina. Londrina-PR-Brasil.

RESUMO: Este estudo objetivou identificar o processo de aprendizado de Administração em Enfermagem no cotidiano de formação, na perspectiva de docentes dessa disciplina. Estudo exploratório-descritivo com abordagem qualitativa, realizado entre julho e setembro de 2012, com docentes de cinco Instituições de Ensino Superior, privadas e seis públicas do sul do Brasil. A análise de conteúdo das entrevistas de 25 docentes permitiu a emersão de duas categorias: processo de aprendizado no cotidiano de formação de Administração em Enfermagem e avaliação do processo de aprendizado de Administração em Enfermagem. Os resultados indicam que persistem currículos compartimentalizados, os cursos carecem de diversificação de cenários de prática e formação docente específica, aparece a utilização de estratégias/metodologias ativas. Indica recomendações às instituições de ensino e aos docentes para a melhoria das ações no processo de aprendizado em Administração em Enfermagem. DESCRITORES: Pesquisa em administração de enfermagem; Educação superior; Docentes de enfermagem; Prática do docente de enfermagem.

\section{PERCEPTION OF TEACHERS ABOUT THE LEARNING PROCESS IN NURSING ADMINISTRATION}

\begin{abstract}
This study aimed to identify the Nursing Administration learning process in daily education from the perspective of faculty members teaching this subject. Exploratory and descriptive study with a qualitative approach, undertaken between July and September 2012, involving faculty members from five private and six public higher education institutions in the South of Brazil. The content analysis of 25 faculty members' interviews revealed two categories: learning process in daily Nursing Administration education and assessment of the Nursing Administration learning process. The results indicate that compartmentalized curricula continue to exist, that the course lacks diverse practical scenario and specific teacher training, while the use of active strategies/methods appears. The study formulates recommendations for the teaching institutions and the faculty members in order to improve the actions in the Nursing Administration learning process. DESCRIPTORS: Nursing administration research; Higher education; Faculty Nursing; Nursing faculty practice.
\end{abstract}

\section{PERCEPCIÓN DE DOCENTES SOBRE EL PROCESO DE APRENDIZAJE EN ADMINISTRACIÓN DE ENFERMERÍA}

RESUMEN: Este estudio tuvo el objetivo de identificar el proceso de aprendizaje de Administración en Enfermería en el cotidiano de formación, en la perspectiva de docentes de esa disciplina. Estudio exploratorio descriptivo con abordaje cualitativo, realizado entre julio y setiembre de 2012, con docentes de cinco Instituciones de Enseñanza Superior, particulares, y seis públicas del sur de Brasil. El análisis de contenido de las entrevistas de 25 docentes resultó en dos categorías: proceso de aprendizaje en el cotidiano de formación de Administración en Enfermería y evaluación del proceso de aprendizaje de Administración en Enfermería. Los resultados apuntan que persisten currículos compartimentalizados, los cursos necesitan de diversificación de escenarios de práctica y formación docente específica, aparece la utilización de estrategias/metodologías activas. Son necesarias recomendaciones a las instituciones de enseñanza y a los docentes para mejorar acciones en el proceso de aprendizaje en Administración en Enfermería. DESCRIPTORES: Investigación en administración de enfermería; Educación superior; Docentes de enfermería; Práctica del docente de enfermería.

*Artigo extraído da Dissertação intitulada: Percepção de docentes sobre o processo de aprendizado de Administração em Enfermagem. Faculdade Pequeno Príncipe, 2013. 


\section{INTRODUÇÃO}

Na era da informação, o espaço de saber do docente cede lugar ao de mediador e problematizador do aprender: ele passou a ser visto como aquele que desafia os estudantes, mostrando-lhes, entre as várias possibilidades de aprendizagem, caminhos que poderão ser percorridos. A forma tradicional de ensino nas instituições era centrada na figura do docente, sendo este tratado como o 'dono do saber'. O cenário está em transformação, pois o processo de aprendizado envolve o ensino e a aprendizagem e os mecanismos pelos quais o estudante e docente chegam até ele. O processo de aprendizado é a capacidade de se adaptar, de modificar e melhorar o comportamento e as respostas, tendo o docente como elemento essencial para a mediação da trajetória de ensinar e aprender ${ }^{(1)}$.

Este processo está envolto por múltiplos fatores que se implicam mutuamente e que, embora possamos analisar em separado, fazem parte de um todo que depende, quer na sua natureza, quer na sua qualidade, de uma série de condições internas e externas ao sujeito. É decorrente da assimilação do conhecimento pelo sujeito e também da modificação de estruturas mentais já existentes $^{(2)}$. O processo de aprender é pessoal, de construção e de partilha de experiências passadas que influenciam as aprendizagens futuras.

Há método para ensinar, porém não há método para se aprender, pois o aprendizado não pode ser circunscrito nos limites de uma aula, da audição de uma conferência, da leitura de um livro(1).

Reportando tais considerações para a enfermagem tem-se que, durante o desenvolvimento do processo de aprendizado de administração em enfermagem é exigido que sejam contemplados conhecimentos sobre as concepções teóricas que permeiam a gestão em saúde, a formação de recursos humanos nesta profissão, bem como a tomada de decisão para a obtenção dos resultados desejados. Estes conhecimentos estão previstos nas Diretrizes Curriculares Nacionais (DCNs) para os Cursos de Graduação em Enfermagem ${ }^{(3)}$, para a atuação do futuro enfermeiro no Sistema Único de Saúde (SUS).

Para que o processo de aprendizado, particularmente o de administração em enfermagem, alcance potencial transformador, é requerido um novo enfoque, novas tendências técnico-pedagógicas, alterações nas estratégias no âmbito do processo formativo, com vistas a uma educação emancipadora, justamente porque favorece a reflexão do cotidiano, o questionamento e a modificação social. Com isso, se originam discussões mais aprofundadas nas Instituições de Ensino Superior (IES) acerca da possibilidade de implementação de processos de aprendizado inovadores. Estas discussões podem modificar a maneira da formação de recursos humanos de saúde para o SUS, com relação às especificidades regionais ${ }^{(4)}$.

Contudo, é importante que os protagonistas envolvidos neste contexto sejam constantemente ouvidos com o intuito de se investigar os benefícios, bem como a efetividade e necessidades de aperfeiçoamento destas novas práticas. Assim, a partir da contextualização, propõe-se como objetivo deste estudo identificar o processo de aprendizado de Administração em Enfermagem no cotidiano de formação, na perspectiva de docentes dessa disciplina.

\section{MÉTODO}

Pesquisa exploratório-descritivo com abordagem qualitativa, uma vez que esta possibilitou uma maior aproximação com o cotidiano e as experiências vividas pelos próprios sujeitos da pesquisa ${ }^{(5)}$. Realizada em cinco IES privadas e seis públicas do estado do Paraná que possuem o curso de Graduação em Enfermagem reconhecido pelo Ministério da Educação e Cultura (MEC). Foram convidados a participar 40 docentes que ministravam a disciplina de Administração em Enfermagem, com aceite de 25 deles, sendo 10 de instituições privadas e 15 de instituições públicas.

Os preceitos éticos obedeceram à Resolução 196/96 do Conselho Nacional de Saúde ${ }^{(6)}$ e a coleta dos dados deu-se após a aprovação do projeto de pesquisa pelo Comitê de Ética em Pesquisa (CEP) com Seres Humanos sob o registro $n^{\circ} 1067 / 12$. Para preservar o anonimato dos participantes optou-se, por identifica-los com as codificações: Instituição Pública - Pub 1, Pub 2, Pub 3...; Instituição Privada - Priv 1, Priv 2, Priv 3...

Foram usados como critérios de inclusão: docente da disciplina de Administração em Enfermagem (ou designação similar) e pertencer a uma IES privada ou pública, com curso reconhecido pelo MEC. Foram excluídos os 
docentes do curso que ministravam outras disciplinas e os que estavam de licença ou atestado médico no período de pesquisa.

Para a coleta das informações foi utilizada entrevista semiestruturada, gravada no período de julho a setembro de 2012, tendo como questão norteadora: qual a percepção atribuída ao processo de aprendizado de Administração em Enfermagem no cotidiano de formação, na sua perspectiva como docente dessa disciplina, em instituição de ensino superior? Para a análise das informações seguiram-se os passos da análise de conteúdo, que incluí: 1. Pré análise; 2. Exploração do material; 3. Tratamento dos resultados obtidos, a inferência e a interpretação( ${ }^{(7)}$.

\section{RESULTADOS}

A análise qualitativa fez emergir duas categorias, com as seguintes denominações: Processo de aprendizado no cotidiano de formação de Administração em Enfermagem e Avaliação do processo de aprendizado de Administração em Enfermagem.

\section{Processo de aprendizado no cotidiano de formação de Administração em Enfermagem}

O processo de aprendizado articula os papéis de docente e estudante, em que o docente assume a postura de mediador, ajudando o estudante a analisar as fontes de informações que possuem as melhores evidências sobre um determinado fato ou assunto. Esse processo centra sua atenção não mais na função de transmissão de informações, mas sim, na mediação do saber com o uso de diversificadas estratégias metodológicas e avaliativas.

\section{Estratégias do Processo de Ensino-Aprendizagem}

Entre as estratégias de ensino-aprendizagem, no cotidiano de formação de Administração em Enfermagem, são citadas pelos participantes as estratégias metodológicas, as quais buscam incorporar tendências que impulsionam para a transformação. Pelo depoimento a seguir, é possível perceber o movimento que se instaura com novas metodologias, rompendo com o modelo tradicional que traz em si o racionalismo cartesiano, para um modelo aberto, com distintos cenários e com liberdade para a diversidade.

Metodologias mais dinâmicas de ensinoaprendizagem, alguma metodologia mais reflexiva, também se procura trabalhar algumas aulas não tão expositivas, mas dentro de uma perspectiva de uma educação mais problematizadora. (Pub 9)

Os docentes referem o uso da aula expositiva dialogada, articulada a outras estratégias, como resolução de problemas ou situações, estudos de caso, GV-GO (Grupo de Verbalização e Grupo de Observação), simulações, seminários, plataforma de ensino à distância e recursos visuais de multimídia, como exemplificam os trechos a seguir:

Utilizo aulas expositivas e dialogadas, discussão de situações, de casos, GV-GO, simulação de casos, seminários, pensando no aluno como coparticipante no seu processo de formação. (Priv 1)

Simulação também a gente usa bastante, porque, essa coisa de aprender a fazer as coisas, todo mundo aprende, nem que você repita dez vezes, ele vai aprender. (Priv 4)

A utilização de artigos mostrou-se presente no cotidiano dos docentes, abrindo possibilidades não apenas para obter o conhecimento específico da disciplina de administração, mas iniciar o convívio com a pesquisa, prática baseada em evidências, técnicas que irão contribuir para o exercício profissional futuro. O ensino com pesquisa é uma estratégia utilizada com sucesso, pois ativa a curiosidade, o espírito crítico de ler e analisar artigos publicados e fazer as conexões com o seu processo de aprendizado:

Eu também utilizo muito os artigos novos publicados, aí o estudante com isso já trabalha, descobre, cria também e constrói um conhecimento bastante palpável, concreto, mas, com uma boa fundamentação teórica. (Pub 10)

As visitas técnicas foram citadas como oportunidades valiosas de aprendizagem de 
Administração em Enfermagem. A vivência na prática cotidiana auxilia o aprender a fazer, pois os estudantes entram em contato direto com as atribuições do enfermeiro na gerência do processo de cuidar e de instituições de saúde, como ilustra a seguinte fala:

A gente fazia incursões de visitas técnicas em alguns serviços que fossem interessantes. Isto sempre foi fundamental para o aluno conhecer diferentes realidades e especificidades de atuação do enfermeiro em cada uma delas. (Pub 3)

As dinâmicas e vídeos são elencados pelos professores participantes da pesquisa para trabalhar temas como motivação, liderança e até mesmo para descontrair o aluno. A Dinâmica de Grupo preconiza uma visão interacionista, dialógica e construtiva dos atores que participam do processo de ensino e aprendizagem, conforme destaca um dos docentes:

Algumas dinâmicas, alguns vídeos, quando eu vou trabalhar, por exemplo, motivação, liderança, dentro do contexto da administração. (Pub 2)

Os docentes têm utilizado o planejamento como forma de envolvimento do estudante, para que possa colocar em prática situações que este irá enfrentar no futuro desempenho profissional, sempre de acordo com os conteúdos necessários a esta habilidade. Os planejamentos citados foram estratégicosituacional, estratégico-participativo e planejamento hipotético para despertar o interesse, pensamento estratégico do estudante na vivência desta estratégia, conforme discurso aqui exemplificado:

Trabalho com planejamento, eu utilizo várias correntes de pensamento do planejamento, desde estratégico-situacional, planejamento estratégico-participativo, a epidemiologia no planejamento e o planejamento propriamente dito na enfermagem. (Pub 11)

\section{Oportunidades de Aprendizado}

Observa-se que os docentes indicaram a carga horária teórica, prática/supervisionada da disciplina de Administração em Enfermagem, predominante no último ano de formação, sendo dividida entre a atenção básica (Unidades de Saúde) e atenção terciária (Hospitalar). Merece destaque outros serviços em que o enfermeiro atua como home care, atendimento pré-hospitalar, setores como centro cirúrgico e central de material e esterilização. Em relação aos conteúdos teóricos, a carga horária varia de 36 a 168 horas e, para as aulas práticas, de 30 a 144 horas. A maior oportunidade de aprendizado no estágio curricular supervisionado tem 270 a 900 horas.

As principais atividades relatadas para proporcionar 'Oportunidades de Aprendizado' ao aluno, no desenvolvimento em campo estão relacionadas às competências preconizadas pelas DCNs. Além das oportunidades de conhecimento em diferentes cenários relacionados às questões administrativas, predominam a gestão do cuidado e a gestão dos serviços de saúde. Entre elas incluem-se a problematização da realidade, identificação dos problemas e estabelecimento das ações de intervenção, envolvendo o conhecimento do perfil da população, recursos humanos disponíveis nos serviços e educação continuada. Relatam a vivência do cuidado direto aos pacientes inter-relacionada aos conhecimentos de administração, ao considerar a Sistematização da Assistência de Enfermagem (SAE) uma tecnologia da gestão do cuidado, além do uso de ferramentas de qualidade, modelos de liderança, gerenciamento de resíduos, escala de trabalho, organização do serviço, leis trabalhistas, entre outros, como mencionado nestes recortes:

O enfoque que a gente procura dar nas aulas práticas e no estágio é ele tentar aplicar

O trabalho em equipe, a comunicação, a tomada de decisão. E daí entender a gerência como uma ferramenta de trabalho para o enfermeiro e não um fim, ela é um meio de trabalho, uma forma de o enfermeiro desenvolver seu trabalho. (Pub 1)

Esse estágio é dividido em duas vertentes: uma é gerência do cuidado e uma é gerência do serviço. Então, em uma situação, eu vou ser a professora que vai acompanhar isso dentro do hospital e vai ter outra professora que vai acompanhar isso na rede. (Pub 3)

O aluno consegue verificar o papel do enfermeiro 
enquanto supervisor tentando sempre não dissociá-lo da assistência ao paciente. Tem a oportunidade de realizar cálculo de pessoal, de acordo com o proposto pelo COFEN. Proporcionar a observação da utilização das ferramentas de qualidade, mostrar modelos de liderança, gerenciamento de resíduos, escala de trabalho, organização do serviço, previsão e provisão de materiais. (Priv 10)

\section{Avaliação do Processo de Aprendizado de Administração em Enfermagem}

Os docentes salientam diversos métodos de avaliação, inclusive a utilização de seminários integrados e avaliações integrativas que remetem ao aprendizado de forma contextualizada com outros conhecimentos, além do específico de administração.

\section{Avaliação das Ações no Campo de Prática}

Eles têm utilizado instrumentos de modo a sistematizar e padronizar as avaliações no campo da prática, nos distintos cenários, hospitalar ou de atenção básica, conforme discurso:

Para a parte prática existe um instrumento aos professores, tanto na saúde hospitalar, quanto na saúde coletiva, que o utilizam, sendo que em cada bloco os alunos têm que cumprir determinadas etapas. (Pub 6)

Instrumentos de avaliação com base em conhecimentos, habilidades e atitudes que o estudante necessita desenvolver no estágio ou aulas práticas são referidos pelos docentes desta pesquisa. Salientam que a avaliação por competências possibilita demonstrar se o estudante atingiu ou não as competências propostas pela disciplina. Esta avaliação é exercida pelo docente e pelo enfermeiro supervisor do campo, apoiada em um roteiro que contempla as competências a serem adquiridas. A avaliação do estudante em ambiente real de trabalho, de caráter formativo e contínuo, constitui um dos principais instrumentos do professor. É desenvolvida de forma articulada entre os envolvidos, docentes, enfermeiros de campo e o próprio estudante por meio da autoavaliação, como relatam:

Na parte prática é realizada avaliação periódica, por meio de instrumento. Estão descritas todas as competências, habilidades e atitudes necessárias para o futuro enfermeiro. Essa avaliação é realizada pelo professor e pelo enfermeiro supervisor do campo de estágio. (Priv 8)

Os estágios têm um instrumento que guia a avaliação, alguns tópicos, alguns conhecimentos, habilidades, atitudes que os alunos devem alcançar, o que é esperado que eles desenvolvam ou que eles aprendam ao longo do estágio. (Pub 9)

Destaca-se, nas falas, a utilização do portfólio, uma coleção organizada e devidamente planejada de trabalhos produzidos pelo acadêmico em um dado período de tempo. Procura evidenciar os diversos componentes do seu desenvolvimento e do seu percurso, o que estimula o pensamento reflexivo, facilitando oportunidades para documentar, registar os procedimentos e a própria aprendizagem.

É fornecido um instrumento composto por diversas questões com atividades gerenciais, $o$ portfólio, propostas para realização durante $o$ estágio. (Priv 8)

Portfólio, no qual estarão inseridas as situações vivenciadas no estágio e as reflexões estimuladas pelos professores. (Priv 9)

\section{Avaliação dos Conteúdos/Eixos Teóricos}

A avaliação dos conteúdos/eixos teóricos é realizada por meio de provas escritas com a utilização de questões que exigem reflexão, seminários, trabalhos e participação em sala de aula. Ocorrem avaliações formativas e somativas. É importante destacar a utilização de seminários integrados, possibilitando ao aluno integrar conhecimentos prévios e disciplinares:

Realização de provas, seminários, atividades em sala individuais e grupais. (Priv 10) 
A avaliação é também feita em uma perspectiva ativa de educação, a avaliação ela é do tipo formativa e também somativa, então há os momentos das avaliações teóricas. (Priv 1)

O estudo de caso é relatado como técnica de avaliação, além de estudos dirigidos, relatórios, presença e participação em sala de aula, discussão/dinâmicas de grupo, elaboração de artigo científico, elaboração de projetos para simulação de resolução de situações e propostas gerenciais. É citada a associação por meio de avaliação integrativa ao final do semestre, reunindo as disciplinas do semestre em estudo.

Então, existem os estudos de casos que a gente coloca para que eles possam problematizar o que cada um faria em determinada situação. (Priv 4)

Na parte teórica, por meio de estudos dirigidos, a presença e participação em sala de aula e também, uma prova final. (Pub 9)

\section{DISCUSSÃO}

A problematização é um modelo de ensino comprometido com a educação libertadora, que valoriza o diálogo, desmistifica a realidade e estimula a transformação social por meio de uma prática conscientizadora e crítica. Neste caso, os problemas estudados precisam de um cenário real, para que a construção do conhecimento ocorra a partir da vivência de experiências significativas $^{(8)}$. Percebe-se nos discursos dos docentes a utilização de metodologias ativas, o que não significa que estejam desenvolvendo um ensino inovador, e sim algumas técnicas.

As simulações são espaços protegidos que reproduzem cenários da prática de cuidados à saúde. Os estudantes realizam atendimentos a pacientes simulados, realizam procedimentos em manequins e ou bonecos e são acompanhados por um professor facilitador que avalia o desempenho das capacidades voltadas ao perfil do profissional a ser formado ${ }^{(9)}$. Estas simulações favorecem o processo de ensino aprendizagem, pois demonstram aos alunos situações que podem ser vivenciadas em ambiente que podem cometer erros.
Além disso, eles têm a oportunidade de conhecer e verificar, por meio de aulas práticas, o funcionamento das empresas - o mundo do trabalho -, como forma de rever os conceitos teórico-metodológicos e expressar o diálogo produzido em sala de aula(10). As visitas técnicas articulam as contribuições teóricas à prática e ao mercado, motivando para que o processo de ensino e aprendizagem torne-se efetivo.

Os acadêmicos, mesmo vivenciando a liderança durante o campo de prática, apresentam dificuldades em exercê-la no ambiente hospitalar, as quais relacionam ao reduzido destaque ao ensino da liderança durante a formação acadêmica $^{(11)}$. Destarte, as dinâmicas contribuem sobremaneira para ultrapassar este obstáculo.

O planejamento como estratégia de ensino vem favorecendo o processo de ensino e aprendizagem, pois emerge do contexto vivenciado pelos alunos e sinaliza aos enfermeiros docentes e assistenciais as áreas que necessitam de investimentos para resolução de problemas ${ }^{(12)}$.

Pela diversidade de opções metodológicas citadas pelos docentes, observa-se que há preocupação na concepção do processo de ensino-aprendizagem, porém alterar o currículo e metodologias não garante as mudanças almejadas ou as práticas pedagógicas. Somente é possível afirmar que um currículo mudou efetivamente quando os professores mudaram suas práticas e alteraram suas concepções sobre ensinoaprendizagem $^{(13)}$.

Em pesquisa sobre matriz curricular, obtevese que a carga horária destinada à disciplina de Administração em Enfermagem concentravase no último semestre do curso, indicando a deficiência na distribuição e integração dos conteúdos, o que proporciona uma distância ou dicotomia entre a teoria e a prática ${ }^{(9)}$. $\mathrm{O}$ modelo ideal é construir um currículo em que se privilegie o processo de formação articulado com o mundo do trabalho, que rompa com a dicotomia teoria/prática, através da utilização de estratégias pedagógicas inovadoras, com ensino contextualizado, proporcionando aprendizagem significativa e um futuro profissional mais crítico e compromissado com as questões profissionais e sociais $^{(14)}$.

Com base na carga horária mínima do currículo de enfermagem de 4000 horas, vinte por cento é destinado à disciplina de Estágio Supervisionado(15). Portanto, a variação 
apresentada nesta pesquisa se refere às diferenças entre os currículos das IES estudadas.

Em se tratando da avaliação os docentes entrevistados possuem instrumentos para poder realizá-la. Em pesquisa um grupo de docentes relata a construção de um instrumento para a avaliação do Estágio Curricular em Administração em Enfermagem, que objetivou minimizar a dicotomia entre teoria e prática. Concluem que facilitou a avaliação do estudante sustentada em uma metodologia ativa de ensino-aprendizagem significativa ${ }^{(16)}$.

O portfólio é utilizado como método de avaliação formativa no processo de ensino e aprendizagem da disciplina de Administração em Enfermagem, constituindo-se em um modo diferente da avaliação tradicional. Ele promove o desenvolvimento da capacidade críticoreflexiva e consequentemente a construção de conhecimento $^{(17)}$.

As técnicas de avaliação elencadas pelos docentes são coerentes com a literatura correlata quando se fala em metodologias inovadoras de ensino e aprendizagem. O seminário, dentre as estratégias de avaliação, permite ao estudante um modelo de educação mais participativo e reflexivo. Propicia despertar diferentes operações de pensamentos, como: análise, interpretação, crítica, levantamento de hipóteses, busca de suposições, obtenção e organização de dados ${ }^{(18)}$.

Para que o aluno seja avaliado de forma global são necessárias distintas abordagens avaliativas da aprendizagem, incluindo levantamento, análise e síntese dos dados, de forma objetiva e subjetiva, possibilitando o diagnóstico dos fatores que interferem no resultado da aprendizagem ${ }^{(10)}$. As estratégias de avaliação precisam informar aos alunos e professores sobre a qualidade da experiência educacional(19). Assim, percebese, que é possível utilizar diversas estratégias de avaliação, desde que favoreçam a que os estudantes tenham insights sobre seu próprio processo educacional.

Por fim, cabe ressaltar que embora existam dificuldades para a prática gerencial do enfermeiro, tanto os impostos pelo mundo do trabalho quanto os desafios de mudança das práticas pedagógicas ao longo da formação acadêmica, percebe-se um movimento de mudança para que as competências gerenciais cabíveis a este profissional possam ser sedimentadas, em uma perspectiva que se distancie progressivamente da anacronicidade do ensino meramente transmissional e, por conseguinte, de uma atuação acrítica $^{(20)}$.

\section{CONSIDERAÇÕES FINAIS}

A pesquisa indica que ainda persistem currículos compartimentalizados, porém denotase que surgem propostas para a utilização de estratégias/metodologias ativas de ensino. Nas oportunidades de aprendizado há variação entre a carga horária teórica e prática nos distintos currículos pesquisados. A maioria dos currículos inclui a disciplina de Administração em Enfermagem no último ano de formação em variados cenários de prática.

A avaliação da prática é realizada por meio de instrumento com base nos conhecimentos, habilidades e atitudes que o estudante necessita desenvolver durante o estágio ou aulas práticas. Esse instrumento demostra se o aluno atingiu ou não as competências propostas pela disciplina; articula a avaliação do docente, enfermeiro do campo e a autoavaliação do estudante. Citam o portfólio reflexivo, o qual facilita oportunidades de aprendizado ao documentar, registrar os procedimentos e a própria aprendizagem.

Para a avaliação dos conteúdos/eixos teóricos são referidas diversas técnicas como, seminários integrados, avaliações integrativas, provas escritas com questões que exigem reflexão, trabalhos, participação em sala de aula, elaboração de artigos.

Ressalta-se a necessidade da incorporação por parte dos docentes e IES do ensino integrado, o qual possibilita o aprendizado de conteúdos de administração em diferentes contextos e diferentes níveis de complexidade, tendo como base o planejamento.

Considera-se que a pesquisa contribui aos docentes da graduação em enfermagem, conduzindo à reflexão e aprofundamento do conhecimento sobre o processo de aprendizado de Administração em Enfermagem. Nesse sentido, recomenda-se: 1) Redistribuir os conteúdos de forma transversal no currículo, evitando que a inserção do aluno ocorra somente no último ano de formação; 2) Rediscutir a carga horária teórica e prática; 3) Estabelecer maior diversidade de cenários de prática possibilitando ao aluno vivências em todos os níveis de complexidade 
do viver humano; 4) Implementar inovações avaliativas contemplando diferentes abordagens, com base no alcance das competências sugeridas pelas DCNs; 5) Implementar estratégias metodológicas (inovadoras/ativas) no processo de aprendizado; 6) Priorizar que o processo de aprendizado estimule o questionamento, a dúvida, a incerteza diante das demandas do processo de saúde-doença e do processo de trabalho dos profissionais da área de saúde; 7) Envolver os alunos como protagonistas das transformações almejadas no processo de aprendizado de Administração em Enfermagem.

Distante de sanar as discussões sobre a temática vislumbra-se que as colocações ora finalizadas, ainda que embrionárias, possam servir como fulcro a outras pesquisas e, sobretudo, como mola propulsora para possíveis reformas curriculares nos cursos de graduação em enfermagem, objetivando a formação de enfermeiros cada vez mais capazes de melhorar os cenários onde atuarem.

\section{REFERÊNCIAS}

1. Semim GM, Souza MC, Corrêa AK. Professor as a facilitating agent of the teaching learning process: perspective of the nursing student. Rev. gauch. enferm. [Internet] 2009;30(3). [acesso em 01 jul 2014]. Disponível: http://www.ncbi.nlm.nih.gov/ pubmed/20187430

2. Caveião C, Hey AP, Montezeli JH. Administração em enfermagem: um olhar na perspectiva do pensamento complexo. REUFSM. [Internet] 2013;3(1). [acesso em 01 jul 2014]. Disponível: http://cascavel.ufsm.br/ revistas/ojs-2.2.2/index.php/reufsm/article/view/7176

3. Ministério da Educação (BR). Diretrizes Curriculares Nacionais dos Cursos de Graduação em Enfermagem. Parecer $n^{\circ}$ 1.133/2001. Brasília: MEC; 2001.

4. Vargas ROLCO, Wall ML, Peres AM. The problematization method applied to the subject nur sing administration. Invest. educ. enferm. 2012;30(2):269-76.

5. Minayo MCS. O desafio do conhecimento: Pesquisa qualitativa em saúde. 1 ed. São Paulo: HUCITEC, 2007.

6. Ministério da Saúde (BR). Conselho Nacional de Saúde. Diretrizes e normas regulamentadoras de pesquisa envolvendo seres humanos. Resolução n. 196, de 10 de outubro de 1996. Brasília [Internet]. 1996. [acesso em 20 nov 2014]. Disponível: http://bvsms.saude.gov. br/bvs/saudelegis/cns/1996/res0196_10_10_1996.html
7. Bardin L. Análise de conteúdo. São Paulo (SP): Edições 70; 2011.

8. Carbogim FC, Friedrich DBC, Püschel VAA, Oliveira LB, Nascimento HR. Paradigma da integralidade no currículo e nas estratégias de ensino em enfermagem: um enfoque histórico-cultural. Rev. enferm. Cent.Oeste Min. 2014;4(1):961-70.

9. Souza AF, Jardim VMR, Coimbra VCC. A experiência de construção e implementação de um currículo de enfermagem orientado a partir do Sistema Único de Saúde. In: Anais do $2^{\circ}$ Seminário Nacional de Diretrizes de Enfermagem na Atenção Básica em Saúde; 2009 Ago 20-22; Recife, Brasil. Recife: Associação Brasileira de Enfermagem; 2009.

10. Kalinovki CE, Massoquetti RMD, Peres AM, Larocca LM, Cunha ICKO, Gonçalves LS, et al. Metodologias participativas no ensino da administração em Enfermagem. Interface, Comun., Saúde, Educ. [Internet] 2013;17(47) . [acesso em 01 jul 2014]. Disponível: http:// dx.doi.org/10.1590/S1414-32832013005000029

11. Amestoy SC, Backes VMS, Thofehrn MB, Martins JG, Meirelles BHS, Trindade LL. Nurses' perception of the teaching-learning process of leadership. Texto \& contexto enferm. [Internet] 2013;22(2). [acesso em 01 jul 2014]. Disponível: http://dx.doi.org/10.1590/S010407072013000200024

12. Melleiro MM, Tronchin DMR, Ciampone MHT. O planejamento estratégico situacional no ensino do gerenciamento em enfermagem. Acta Paul. Enferm. [Internet] 2005;18(2). [acesso em 01 jul 2014]. Disponível: http://dx.doi.org/10.1590/S010321002005000200008

13. Moraes MAA, Manzini EJ. Concepções sobre a aprendizagem baseada em problemas: um estudo de caso na Famema. Rev. bras. educ. med. [Internet] 2006;30(3). [acesso em 01 jul 2014]. Disponível: http:// dx.doi.org/10.1590/S0100-55022006000300003

14. Mitre SM, Siqueira-Batista R, Girardi-de-Mendonça JM, Morais-Pinto NM, Meirelles CAB, Pinto-Porto C, et al. Metodologias ativas de ensino-aprendizagem na formação profissional em saúde: debates atuais. Cienc. saude colet. 2008;13(Suppl 2):2133-44.

15. Ministério da Educação(BR). ParecerCNE;CESn. 33/2007, de 1 de fevereiro de 2007. Dispõe sobre a carga horária do curso de graduação enfermagem e sobre a inclusão do percentual destinado do estágio supervisionado na mesma carga horária. Brasília: MEC; 2007.

16. Prado C, Freitas GF, Pereira IM, Mirai VL, Leite MMJ. Avaliação no estágio curricular de administração em enfermagem: perspectiva dialética. Rev. bras. enferm. [Internet] 2010;63(3). [acesso em 01 jul 2014]. Disponível: http://www.redalyc.org/ pdf/2670/267019593023.pdf 
17. Alves ED, Ribeiro LSN, Guimarães DCSM, Costa CMA, Peixoto HM, Martins EF, et al. Moodle-fólio para o ensino em saúde e enfermagem: avaliação do processo educacional. REE. [Internet] 2012;14(3):473-82. [acesso em 01 jul 2014]. Disponível: http://www.revistas.ufg. br/index.php/fen/article/view/19109

18. Prado C, Pereira IM, Fugulin FMT, Peres HHC, Castilho V. Seminars in dialectical perpspective: experience in the nursing administration discipline. Acta Paul. Enferm. [Internet] 2011;24(4). [acesso em 01 jul 2014]. Disponível: http://dx.doi.org/10.1590/S010321002011000400021

19. Lino MM, Backes VMS, Ferraz F, Reibnitz KS, Martini JG. Posturas pedagógicas adotadas no ensino de enfermagem e saúde na Região Sul do Brasil. Rev. bras. enferm. [Internet]. 2011;64(1) [acesso em 01 jul 2014]. Disponível: http://dx.doi.org/10.1590/S003471672011000100022

20. Montezeli JHM, Peres AM. Competência gerencial do enfermeiro: conhecimento publicado em periódicos brasileiros. Cogitare enferm. [Internet] 2009; 14(3) [acesso em 21 set 2014]. Disponível: http://ojs.c3sl.ufpr. br/ojs/index.php/cogitare/article/view/16189/10707 